\title{
Localization of lesion in patients with idiopathic orthostatic hypotension
}

Sir :

Idiopathic orthostatic hypotension is a fascinating condition and it is certainly important to localize the lesion. The author (Ibrahim, M. M. (1975), British Heart fournal, 37,868 ) is justified by his evidence in concluding that the lesion is probably somewhere in efferent sympathetic pathways. The trouble is that the paper produces a powerful déjà vu phenomenon. Johnson et al. (1966) reported patients in whom similar tests were done with similar conclusions, and in whom a fall-out of cells in the intermediolateral column was found at necropsy. This finding is compatible with degeneration of cell bodies of preganglionic cells. Since then other papers have supported this view and added further evidence. Among these are Vanderhaeghen, Perier and Sternon (1970), Bannister (1971), and Bannister and Oppenheimer (1972).

The condition and its association with degeneration elsewhere in the nervous system, and the many reports on the subject are reviewed in the chapter on arterial hypotension in 'Disorders of the Autonomic Nervous System', Johnson and Spalding (1974).

\section{J. M. K. Spalding, Department of Neurology, \\ The Radcliffe Infirmary, Oxford.}

\section{References}

Bannister, R. G. (1971). Degeneration of the autonomic nervous system. Lancet, $2,175$.

Bannister, R., and Oppenheimer, D. R. (1972). Degenerative disease of the nervous system associated with autonomic failure. Brain, 95, 457.

Johnson, R. H., Lee, G. de J., Oppenheimer, D. R., and Spalding, J. M. K. (1966). Autonomic failure with orthostatic hypotension due to intermediolateral column degeneration. Quarterly fournal of Medicine, 35, 276.

Johnson, R. H., and Spalding, J. M. K. (1974). Arterial hypotension. In Disorders of the Autonomic Nervous System, p. 90. Blackwell Scientific Publications, Oxford.

Vanderhaeghen, J -J., Perier, O., and Sternon, J. E. (1970). Pathological findings in idiopathic orthostatic hypotension. Archives of Neurology, 22, 207.
This letter was shown to Dr. Ibrahim who replies as follows:

Sir:

I am aware of many of the pathological studies that showed evidence of degenerative changes in cell bodies of preganglionic cells as Dr. Spalding indicated in his letter. However, I wonder if Dr. Spalding is familiar with other pathological studies in patients with idiopathic orthostatic hypotension where no lesions were found in preganglionic cells or efferent sympathetic fibres (Lewis and Dunn, 1967) and lesions in afferent or central pathways were suggested (Bannister, Ardill, and Fentem, 1967). That the automatic defect may involve afferent baroreceptor impulses as well as efferent vasoconstrictor pathways with a reduction in vascular stores of norepinephrine was indicated by the studies of Abboud and Eckstein (1966). Love et al. (1971) using physiological tests similar to those in my study described patients with lesions in afferent autonomic fibres without involvement of efferent fibres. It is unwise to suggest that all patients with idiopathic orthostatic hypotension have an efferent sympathetic disease, and, therefore, it is unfair to mention that my paper produces a powerful déjà $v u$ phenomenon. Furthermore, I believe that Dr. Spalding is not aware that one of the main objectives of my study was to provide a plan to investigate in a systematic way the different components of the baroreceptor reflex arc that can help to localize-on clinical grounds-the site of the lesion in other diseases of the autonomic nervous system.

M. Mohsen Ibrahim, Department of Cardiology, Cairo University, 1 El-Sherifein St., Cairo, Egypt. 


\section{References}

Abboud, F. M., and Eckstein, J. W. (1966). Autonomic defect in orthostatic hypotension. Fournal of Laboratory and Clinical Medicine, 68, 851.

Bannister, R., Ardill, L., and Fentem, P. (1967). Defective autonomic control of blood vessels in idiopathic hypotension. Brain, 90, 725.
Lewis, H. D., Jr., and Dunn, M. (1967). Orthostatic hypotension syndrome. American Heart fournal, 74, 396.

Love, D. R., Brown, J. J., Chinn, R. H., Johnson, R. H., Lever, A. F., Park, D. M., and Robertson, J. L. S. (1971). Plasma renin in idiopathic orthostatic hypotension: differential response in subjects with probable afferent and efferent autonomic failure. Clinical Science, 41, 289. 